\title{
Infection Control in design and construction work
}

Article

Accepted Version

Collinge, W. H. (2015) Infection Control in design and construction work. Health Environment Research and Design Journal, 8 (3). pp. 68-79. ISSN 1937-5867 doi:

https://doi.org/10.1177/1937586715577369 Available at https://centaur.reading.ac.uk/40620/

It is advisable to refer to the publisher's version if you intend to cite from the work. See Guidance on citing.

To link to this article DOI: http://dx.doi.org/10.1177/1937586715577369

Publisher: Center for Health Design

All outputs in CentAUR are protected by Intellectual Property Rights law, including copyright law. Copyright and IPR is retained by the creators or other copyright holders. Terms and conditions for use of this material are defined in the End User Agreement.

\section{www.reading.ac.uk/centaur}

\section{CentAUR}

Central Archive at the University of Reading

Reading's research outputs online 


\section{ABSTRACT}

3 Objective: To clarify how infection control requirements are represented, communicated and

4 understood in work interactions through the medical facility construction project lifecycle.

5 To assist project participants with effective infection control management by highlighting the

6 nature of such requirements and presenting recommendations to aid practice.

7 Background: A 4 year study regarding client requirement representation and use on NHS

8 (National Health Service) construction projects in the UK provided empirical evidence of

9 infection control requirement communication and understanding through design and construction work interactions.

Methods: An analysis of construction project resources (e.g. infection control regulations; room data sheets) was combined with semi-structured interviews with hospital client employees and design and construction professionals to provide valuable insights into the management of infection control issues.

Results: Infection control requirements are representationally indistinct but also omnipresent through all phases of the construction project lifecycle: failure to recognize their nature, relevance and significance can result in delays, stoppages and re-design work. Construction project resources (e.g. regulatory guidance; room data sheets) can mask or obscure the meaning of infection control issues.

20 Conclusions: A pre-emptive identification of issues combined with knowledge sharing activities amongst project stakeholders can enable infection control requirements to be properly understood and addressed. Such initiatives should also reference existing infection control regulatory guidance and advice. 


\section{Introduction}

Effective infection control management is essential throughout the entire hospital construction project lifecycle, being relevant to briefing and design phase work as well as to the building and operational stages of project activity (Stockley et al. 2006). Despite the development of regulations and guidance by government agencies and health bodies on how best to manage infection control issues, these requirements can still be problematic, potentially resulting in delays, stoppages and re-design work. This paper explores how infection control requirements are represented through the construction project lifecycle and how they are understood by hospital construction project participants (i.e. designers, contractors, sub-contractors, client stakeholders). The paper clarifies how INFECTION CONTROL ISSUES RESIST REPRESENTATION, BECOMING CONFLATED WITH

OTHER MEDICAL FACILITY REQUIREMENTS infection control issues resist representation, becoming conflated with other medical facility requirements through the design and construction discourse; infection control requirements often needing to be unpicked and prioritized by project participants in order to be resolved. It is argued that the meaning of infection control requirements is obscured by their representational indistinctness, so that a pre-emptive identification and mutual sharing of knowledge by project participants is both necessary and important.

The paper uses empirical evidence drawn from a 4-year study of the representation and use of construction project requirements in hospital and medical facility contexts to clarify the processes of communication and understanding occurring when infection control issues are the focus of attention. An analysis of project data resources (e.g. infection regulations; room data sheets) is combined with interviewee insights into the design, construction and 
maintenance process: this combination of evidence providing valuable insights into the management of infection control issues. A series of vignettes drawn from National Health Service (NHS) hospital construction projects in the U.K. highlights how THE OMNIPRESENCE, INTANGIBILITY AND REPRESENTATIONAL INDISTINCTNESS OF INFECTION CONTROL CAN RESULT IN STOPPAGES, DELAYS AND REDESIGN WORK the omnipresence, intangibility and representational indistinctness of infection control can result in stoppages, delays and re-design work, often necessitating complex processes of meaning making between project participants. Such associated processes of making meaning often evade critical analysis and examination, despite their impact upon the design, construction and facility management process. It will be argued that infection control requirements need to be pre-emptively identified as associated guidance is often too generic for the questions at hand: a sharing of knowledge between parties being both important and necessary to prevent delays, stoppages and re-design work from occurring.

The paper begins by reviewing the existing infection control guidance and literature and the construction project lifecycle. The paper notes how infection control requirements are commonly represented in construction project design and construction work (i.e. through briefing statements; regulatory guidance; room data sheets). A research methodology section details the empirical work undertaken and the data collected for the study. This is followed by a focused account of infection control work at different stages of the hospital construction project lifecycle (i.e. design; construction; operation), with vignettes being drawn from NHS hospital construction projects in the UK. These vignettes highlight the omnipresence and representational indistinctness of infection control issues as the significance of obtaining mutual understanding between parties is noted. A following discussion notes how project resources do not necessarily assist in a clarification of issues or concerns relating to infection 
control requirements: a pre-emptive identification of issues and a mutual sharing of knowledge being both necessary and important throughout the medical facility lifecycle. The recommendations presented to assist practitioners reference the invaluable existing literature and guidance on the subject (e.g. Dept. of Health, 2013; Bartley, 2000; Stockley et al., 2006) whilst making some fresh suggestions that reference the observations and insights of the paper. A closing conclusion draws the main arguments of the paper together.

\section{Infection Control and the Construction Project Lifecycle}

The importance of effective infection control management is reflected in governmental guidance and regulations about the subject published in both the U.S. (Agency for Healthcare Research and Quality - AHRQ) and the U.K. (Dept. of Health). In their latest published advice regarding the subject, the UK`s Department of Health (2013) gives detailed instructional guidance for infection control management at the various stages of the construction project lifecycle. As noted by Davies (2013), the design, construction and maintenance of healthcare facilities have a substantial bearing on the risk of developing healthcare-associated infections. Such governmental guidelines are invaluable for NHS staff tasked with infection control work in the UK and offer important information for effective infection control management. Health professionals and academics have also made contributions individually and collectively to the field (e.g. Bartley, 2000; Carter \& Barr, 1997; Stockley et al., 2006) and continue to emphasize their importance (e.g. Hamilton, 2013). In their 2006 paper, Stockley et al. present comprehensive recommendations regarding how best to approach effective infection control management at different phases of the construction project process, giving advice and recommendations that remain valid. However, such publications do not address how the representation of infection control requirements effects communicative interactions occurring in design and construction work 
contexts, nor do they provide tangible examples of how infection control requirements are addressed and resolved. This paper specifically exposes such issues for examination.

The construction project process is traditionally divided into distinct phases that together constitute a lifecycle (figure 1).

\section{[insert figure 1 here]}

As noted by Stockley et al. (2006), infection control is relevant to each of these phases of the construction project lifecycle. It is worth noting that each party engaged upon a project (i.e. the hospital client; design consortia companies; contractors; sub-contractors), at whatever stage of the project lifecycle, will declare their commitment to effective infection control management through policy statements and work contracts. Infection control is commonly viewed as a type of requirement, but the design and construction literature is largely silent on how this particular requirement is dealt with by construction project practitioners. Indeed, although briefing (also known as programming in the U.S.) and design is recognized to be a social process (Green, 1996), with communication being critical for shared interpretations and understandings to take place (Dainty et al. 2006; Emmitt and Gorse, 2007), how different requirements are represented and understood by participating project parties often evades critical analysis. As Blyth and Worthington (2001) have asserted,

"Successful briefing demands attention to communication and how information is structured and passed through the system. Designers speak different languages to users, yet they must understand the business language of their clients for there to be meaningful communication of needs. Dangers lie in misunderstandings, but also in assumptions where one person interprets something differently from another." (p.12)

Certainly, construction project lifecycle communications between parties are characterized by sign use (e.g. texts; drawings; visualizations) as project actors discuss, co-operate and 
collaborate. Although official codes of practice for construction project management (e.g.

122 Chartered Institute of Building - CIOB, 2010) highlight effective communication as important, the significance of meaning making between parties in acts of communication is often overlooked in briefing and design texts (e.g. Barrett and Stanley, 1999; Blyth and Worthington, 2001). Whilst information exchanges have been called the "fuel of design" (Baldwin et al., 1999, p.155), academics and commentators (e.g. Markus and Cameron, 2002; Kamara et al., 2000; Blyth and Worthington, 2001) have also observed that requirements are "translated" from one communicative form (i.e. words) to another (i.e. schematic drawing; visualization; physical model). While communicative resources such as briefing texts, drawings and images make meanings and shared understandings (Gluch and Raisanen, 2009) in construction project work, it has also been noted how sign communications provide a vital link between the realisations of design and the cognitive interpretations of construction project stakeholders (Collinge and Harty, 2014; Collinge, 2014). From a medical facility construction project perspective, it is important to clarify how infection control requirements are communicated and understood by project participants as effective infection control is recognised as pre-eminently important (Dept. of Health, 2013; Hamilton, 2013).

\section{Research Methodology}

A 4 year study into the design and construction of National Health Service (NHS) hospitals in the UK examined client requirement communication and representation amongst construction project participants (i.e. the hospital client; designers; contractors; sub-contractors). A series of 21 semi-structured interviews with NHS representatives and hospital design and construction professionals clarified building and design work interactions and the use of infection control requirements. Interviews were supplemented by the collection of project materials (e.g. briefing documents; visual images; room data sheets) drawn from medical facility construction projects. It should be noted that none of these materials represented 
infection control issues in any visual or graphical way. This may be explained by infection control requirements not being amenable to visual or graphic representation as neither the infection concept nor measures used to combat them are easily represented in briefing and design communications. Whilst infection control precautions are represented in functioning medical facilities (e.g. hand washing instructions above sinks), this is not the case for communications between project parties engaged in design and construction work. The project materials collected indicate that physical and structural design issues dominate communicative exchanges between client, designers and contractors, as may be expected in the briefing and design phase of a construction project.

The paper will now discuss how infection control requirements are represented at different phases of the construction project lifecycle, exploring how they are understood and resolved by project participants. A series of vignettes of construction project activity are provided to clarify and elucidate the issues underlying infection control communications occurring.

\section{Planning and Initial Representations}

Infection control requirements are associated with the functionality and operation of a medical facility rather than its` physical and structural elements, as the following statements drawn from an Invitation to Participate in Competitive Dialogue (ITPD) briefing document issued to competing construction design teams in the UK indicate:

"It should be noted that venetian blinds and curtains have infection control implications that must be considered and must conform to fire safety standards."

"Bidders should be aware that infection control requirements may influence the type of signage.”

"The use of design to effectively control infection is essential. All current, relevant and developing control standards must be adhered to." 

Control in the Built Environment."

172 As such briefing statements indicate, infection control requirements initially reference 173 specific regulatory guidance together with aspects of design, with the use of words resulting in infection control being presented in a strategically neutral way as text is a neutral conveyor of information (Medway, 1996).

In the U.K., infection control issues are addressed through regulatory guidance and standards, such as Health Technical Memoranda (HTM) and Health Building Notes (HNB) (NHS Estates, 2002). A knowledge of such regulations is necessary for construction project work to comply with required standards. The immediate conflation of infection control requirements between an aspect of design (e.g. curtain material; light fitting; door handles) and appropriate regulatory guidance (e.g. particular cleaning regimes; liquids) requires a relational link to be made by project parties. Such regulatory guidance documents have general applicability for multiple projects, so the onus is upon the project participants to identify and apply the regulations where appropriate. An interviewee noted the ambiguity surrounding infection control issues which the printed regulatory guidance does not assist in clarifying:

"We do try to do as much as we can with HTM but it is not always easy. There is always an ambiguity on what falls down on HTMs... what is considered "must-be" rigid. So that is where there is some ambiguity. Infection control." (Project Manager)

The generality of the regulatory guidance must be matched to the specifics of the construction and design question at hand, with objects, equipment and spaces within facilities needing to comply with codes of practice: an ambiguity over correct interpretation of infection control being an immediate potentiality. So, although infection control appears quite definitive and 
factual (being tied to official instructional regulatory guidance), questions of ambiguity remain, only to be potentially resolved when a specific design proposal is cross-examined closely against infection control requirements. From such initial representations, correct interpretation of infection control requirements and application of appropriate measures remains an open question as they are effectively passed over to the design team to deal with at the appropriate time. As will be noted, in later phases of the construction project lifecycle, infection control is represented through other project communications (e.g. room data sheets). Such communications also impact how infection control is understood and engaged with by construction project parties.

\section{Design phase work}

As previously highlighted, in design work various communicative resources (e.g. schematic drawings; visualizations; artist impressions) are used to convey ideas, concepts and plans between project parties. Neither infection control nor the measures used to combat it are represented visually in such project materials as infection control is not amenable to graphic representation in the design discourse between hospital client and design teams. Despite this representational indistinctness, project stakeholders may still identify infection control issues from project materials used in design work. For example, an NHS Head of Facilities identified infection control requirements from a visual image of a patient room, although the image itself highlighted the furniture fittings, space and decoration of a proposed patient room,

"It is things like around the light switches, if you don`t put protectors around the switches and you have got cheap paint, you get a big grey mark all around it. And it is not dirt, but the perception is that it is dirty which is what the NHS is trying to avoid... When it comes to 
choices of actual colour schemes and fabrics we no longer have chairs like this because you cannot clean fabric chairs to the standard that infection control require."

Infection control may not be explicitly identified or addressed on a design representation, but will still be present nevertheless. Therefore, associated infection control issues need to be identified, extrapolated and resolved. The NHS Head of Facilities provided a further example, when stating,

"They put things in like beautiful uplighters that look gorgeous on the wall but there is no cover on the top and what happens in Summer? They are very bad for hospitals: they are almost impossible to keep clean because domestics are not allowed to touch electrical things. These uplighters constantly cause problems; patients complain that they are filthy because they get filled with flies and dust. And people sitting in the waiting room look around and see these and think "what is that?"

Possessing knowledge of infection control issues and sharing that knowledge with other parties is critical to effective infection control: the decision to use a certain fabric or to use lights without covers may have associated infection control issues. The representational indistinctness of infection control in design phase work means that either client, designers or contractors must be aware of them and take that extra step of addressing them. It is very possible that such issues are passed over in design phase work as the infection control regulations require a link to be made between a design issue and the official guidance. As the examples indicate, project parties may have advanced levels of infection control knowledge but sharing that knowledge at an appropriate time is important as the requirements themselves are not explicitly represented through sign communications.

\section{Construction and fitting-out}


240 In the construction and fitting-out phase, when a facility is built and rooms/spaces are

241 equipped, infection control requirements are important again. If refurbishment work is

242 required in an existing hospital, infection control is a particular priority because operational

243 hospitals are highly sensitive environments where construction work has obvious

244 implications for patient care (i.e. noise; dust; vibrations). Understanding how infection

245 control requirements are represented in such work is informative. Room data sheets are

246 commonly produced by hospital clients prior to the equipping of specific rooms, being

247 divided into distinct sections (e.g. Environmental Data; Room Design Character; Schedule of

248 Components). Figure 2 is a room data sheet drawn from the project materials collected for

249 the study.

250 [insert figure 2 here]

251 An interviewee elaborated upon the use of room data sheets:

252 "Room data sheets are provided in draft form. As a result, in theory you get fully loaded

253 drawings. And it may take more than one attempt to fine tune it where the sheet needs to be

254 signed off by stakeholders. There is a series of meetings where architects, principal

255 contractors and client representatives come together and find consensus in terms of what is

256 required, the function of the room, its purpose, occupants and equipment." (NHS

257 Commissioning Manager)

258 As indicated on figure 2, room data sheets reference infection control requirements as well as

259 other issues such as room fittings and window/door specifications. They are instructional

260 documents to provide designers with information needed to transform a design into a physical

261 reality. Infection control issues are addressed through textual reference to regulatory

262 guidance: 
"It lists activities, what is going to happen in the room...so there is a list which enables architects to design rooms in terms of the HTM, HBN regulations. They will come up with a draft and will list how many personnel will be in the room, the planning relationships between rooms and additional notes.” (NHS Commissioning Manager)

Although room data sheets give direct instructions to designers (e.g. type and quantity of room components), the use of words effectively closes down interpretive possibilities. Text often closes down interpretative possibilities rather than opening them up (Medway, 1996), with the text and box formatting of the sheets representing room activities as separate, discreet events as room components are separated from activities. An interviewed NHS Design Development Manager clarified how room data sheets do not necessarily assist in resolving infection control issues when it comes to detailed design work. Referring to potential dust accumulation on cabling above a patient operating table, the room sheet instruction and regulatory guidance needed to be supplemented with further activities and materials:

"As far as infection control, it was a dust collector...but the designers could not think about the set-up of the Endoscopy room, so we took them there to look. The same with the Decontamination Service with the washer disinfectant and an Endoscopic Reprocessing Unit. We also provided photographs of pieces of equipment that were supplemented to the brief because although the brief described a room, you realise they didn't understand what you were saying. And they are building people, not clinical people. And healthcare moves at such a fast pace, you wouldn't expect them to know the clinical functionality or the procedure within a room...So I wouldn`t just depend on a brief... If it was just a line in the brief, I don`t think you would get such a good end product." 
The insight reveals how the challenge of representing infection control leads the hospital client to supplement the brief with photographs, a physical visit to an existing facility and verbal explanation: these extra materials and communications being needed to educate designers about the infection control issue. So, whilst the room data sheets flag up the requirement, they do not clarify the issues; the text and box formatting masking and dividing issues: photographs, physical visit plus verbal explanation being needed for understandings to be shared between client and designers. In this instance, spoken explanation may have been particularly important as just a physical visit or photograph may not have been adequate to explain the issue effectively.

By using pre-formatted headings (e.g. Activities; Personnel; Environmental Data), the room data sheets divide subject matter, potentially creating ambiguities that need to be untangled.

Additionally, by directing designers to regulations (e.g. "Finishes to comply with performance requirements for Building Elements used in Healthcare Facilities 8941:0.6 England) and individual room components, data sheets not only divide components from regulations, but distance components from their actual use in the room space. Whilst defining a relationship between Trust and designers (being instructional and authoritative), the sheets also define a relationship between room contents and related regulations as requirements are divided from regulations and objects from activities. The sheets also give the impression that issues relating to room functionalities have already been resolved (or can be dealt with quickly): the sheet format suggesting any issues are amenable to quick turnover and resolution. However, the cable dust story indicates how room data sheets may mask issues rather than flag up their significance: the text communication and instructional tone adding urgency to the tasks detailed rather than prompting the project parties to think reflectively about their work. Certainly, designers and contractors are not actively encouraged to query and question the information on the sheets. 
311 At this stage of the construction project lifecycle, the client may be eager to complete and equip the medical facility, and the room data sheets assist this objective by closing down interpretive possibilities through the delivery of commands and data using text. However, as noted, TEXT CAN OBSURE FUNCTIONAL REALITIES AND CONFLATE, RATHER THAN CLARIFY INFECTION CONTROL ISSUES text can obscure functional realities and conflate, rather than clarify infection control issues, complicating the fitting out process as a result.

\section{Operation and Maintenance}

INFECTION CONTROL ISSUES RESONATE BEYOND PLANNING, DESIGN AND

FACILITY Infection control issues resonate beyond planning, design and construction to the operation and maintenance of a medical facility. Interviewees provided further insights regarding how infection control issues are dealt with in these phases of the construction project lifecycle. An NHS Project Manager commented,

"Misinformation or misunderstanding over infection control can be transferred down the line from principal contractor to sub-contractors. They see the physical aspects, but they can`t see the consequences of their actions...it is blind to them. It is a blind aspect."

A Project Manager provided a tangible example of this occurrence happening:

"There is a process and there is a way of going about that process. I can say to somebody that I need that floor cleaning and he could turn up with a dirty mop and that is not good enough for a hospital environment. It has to be absolutely spot on. Just something simple like that can cause us a massive problem on infection control." identification to misinterpretation of an infection control issue. Although contractors may 
express commitment to infection control management through contractual agreements with the client (expressing knowledge and experience in such matters), the omnipresence of infection control can be lost in the cut and thrust of busy operational maintenance work. This results in further education and learning work, as noted by another interviewee:

"Sometimes you have to go through an educational process because a principal contractor will put forward contractors who have never been in a hospital environment and they will need educating on what is required and expected. So there is a gap between the principal contractor who say they have health experience and the subcontractors who have not. They will sell themselves on that and then employ people who have not got the experience. So it is a big shortfall. ” (NHS Building Services Engineer)

Verbal and written commitment to infection control measures may not translate to actions on the ground, with infection control implications of particular tasks being missed by contractors working on a job. The NHS Head of Facilities clarified how discussion and communication is key to prevent poor infection control practices from occurring:

"We have a policy for contractors and if they do not comply, we will throw them off site. Sometimes subcontractors or contractors will forget to tell me what they are going to be doing and they will crawl through the corridor ceiling pulling wires through at night when it is quiet. But they won't have told my staff and in the morning the main corridor will be covered in dust from the ceiling. They thought it was a good time to do the work but they were forgetting it is a hospital. So when they do that kind of work, I insist they let us know so we can clinically clean the area before it opens the next morning."

The example illustrates how communication and a pre-emptive identification of potential problems is important for effective infection control management as infection control issues can effectively slip under the radar unless identified and addressed. Again, the 
representational indistinctness of infection control requirements can have adverse effects in the hospital environment.

\section{Discussion}

The paper has discussed the nature of infection control requirements through different phases of the construction project lifecycle. The importance of communication and a pre-emptive identification of infection control issues has been emphasized through illustrative vignettes of practice. It has been noted how infection control requirements resist representation, potentially creating problems for designers, contractors and the hospital client. Project resources such as briefing statements, regulatory guidance and room data sheets do not necessarily assist in a clarification of issues or concerns relating to infection control requirements as design resources such as schematic plans, drawings, images and visualisations may not represent infection control requirements in any tangible way. When it is considered that infection control requirements may merge with other requirements in hospital construction project work (e.g. a light fixture may be visually attractive but functionally questionable from an infection control perspective), infection control requirements often require conversation and discussion between project parties for adequate understandings to be made. This process of shared meaning making requires attention, collaboration and time. The making and sharing of meaning is an aspect of construction project work largely neglected by the construction management literature even though there are repeated calls for more knowledge sharing and participatory design practice. Indeed, although briefing and design work is often reported as problematic, the paper has unravelled the meaning making processes that reside at the heart of interactions between project stakeholders when intangible and representationally indistinct requirements (such as infection control), become the focus of attention between client, designers and contractors. 
In arguing that design concerns meaning, Kazmierczak (2003) pointed out that designs are cognitive interfaces that enable the reconstruction of intended meanings between parties, stating,

"Design needs to be freed from the preoccupation with appearances, and advance to an alternative theoretical model, which relates physical form to cognition and comprehension." (p.47)

The insights of the paper support this contention: representationally indistinct infection control requirements need to be identified and then communicated using the most appropriate method, whether spoken explanation, written text or a combination of resources used collectively. Their indistinctness suggests A PRE-EMPTIVE IDENTIFICATION AND DISCUSSION OF INFECTION CONTROL ISSUES AND A SHARING OF KNOWLEDGE IS DESIRABLE FROM HOSPITAL CLIENT, DESIGN TEAM AND CONTRACTOR PERSPECTIVES a pre-emptive identification and discussion of infection control issues and a sharing of knowledge is desirable from hospital client, design team and contractor perspectives. The paper makes the following recommendations.

\section{Recommendations}

Firstly, the value and importance of existing governmental regulatory guidance and advice regarding effective infection control management must be acknowledged. Parties engaged in any medical facility design and construction work should, as a matter of course, consult the relevant national guidelines and advice (e.g. Dept. of Health, 2013). Additionally, published academic work (e.g. Stockley et al. 2006; Bartley, 2000) concerning infection control should also be consulted and reviewed by dedicated hospital members of staff (i.e. an Infection Prevention and Control Team) and design and construction professionals as they contain valuable information to assist in effective infection control management. Previous 
publications have emphasized the following points for effective infection control management:

- An awareness of the relevant regulatory guidance (e.g. Health Building Notes; Health Technical Memoranda) pertinent to new build or refurbishment projects

- The need for group work and collaborative partnerships between medical facility staff and design and construction professionals to specifically address infection control

- To continually monitor developments during construction work in relation to infection control issues

- The establishment of a dedicated IPC (Infection Prevention Control) team to engage with a project at each phase of the construction project lifecycle (as part of a robust quality control process)

- Plans and work to be signed-off by the dedicated infection prevention control team at each phase of the construction project lifecycle

In addition to the above, some further recommendations can be proposed based upon the paper findings:

- Project participants must be aware of the nature of infection control requirements and issues (i.e. that they resist representation but remain omnipresent in all questions of design and construction)

- Knowledge of effective infection control management may be spread throughout the hospital organisation amongst different stakeholder groups: establishing knowledge sharing processes is important 
- Each specific construction job task (e.g. checking of ceiling wires; demolition of internal/external walls; painting of surfaces); each piece of equipment used (e.g. tools; footwear) and each piece of medical equipment effected (i.e. installation of; use of; maintenance of; cleaning of) will have associated infection control issues. Questions should be directed towards each of these aspects in design and construction work.

- Pre-emptive identification and discussion of infection control can prevent delays, stoppages and re-design work from occurring. Potential solutions would be to highlight infection control risks to contractors coming on-site (e.g. images of a dirty mop/boots in induction manual; images of medical equipment with accompanying question marks)

One further recommendation is made to assist best practice:

- More research work (e.g. focus group workshops) should conducted to identify best evidence-based practice for the communication of infection control requirements through all phases of the construction project lifecycle

Through a mutual sharing of knowledge (both internally and externally to other health service providers), the complexity of infection control issues may be appreciated by all project stakeholders.

\section{Conclusion}

The paper has extended understanding of infection control issues through recognition of how such requirements are communicated and understood through the construction project lifecycle discourse. It has been argued that all parties engaged should recognise the nature of infection control (i.e. its`omnipresence and representational indistinctness) and how it is a potentially problematic issue in the different phases of the construction project lifecycle. 
Information resources used to refer to infection control issues do not address the specifics of the infection control issue at hand, meaning that collective discussion and a sharing of knowledge between project participants is often needed. The vignettes of the paper from different phases of the construction project lifecycle point towards a social explanation and understanding of infection control requirements where communicative interactions are integral to understanding design work practice, confirming the view of both Kao and Green (2002) and Emmitt and Gorse (2007) that design should be a social, co-operative process.

The findings suggest that construction project work is often about the making and sharing of meanings, with communicative resources (i.e. briefing texts; regulatory guidance; room data sheets) being intrinsically important in the meaning making process through their representation of requirements. Whilst understanding client requirements is important, the processes of making meaning from the requirements can be of equal significance to the briefing, design and construction process. The paper has highlighted the complexity of infection control issues and how a pre-emptive identification and discussion of issues is necessary and important in each phase of the construction project lifecycle.

\section{REFERENCES}

Baldwin, A. N., Austin, S.A., Hassan, T.M. \& Thorpe A. (1999). Modelling information flow during the conceptual and schematic stages of building design. Construction Management and Economics, 17, 155-167.

472 Barrett, P. \& Stanley, C. (1999). Better Construction Briefing. Oxford: Blackwell Science. 
475 Blyth, A. \& Worthington, J. (2001). Managing the brieffor better design. London: Spon.

476 Carter, C.D. \& Barr, B.A. (1997). Infection control issues in construction and renovation.

477 Infection control Hospital Epidemiology, 18, 587-596.

478 CIOB (Chartered Institute of Building). (2010). Code of practice for project management for 479 construction and development. Oxford: Wiley-Blackwell.

480 Collinge, W.H. (2014). Briefing as meaning making practice through signs: client

481 requirement representations and transformations in construction project design $(\mathrm{PhD}$ thesis, 482 University of Reading, U.K).

483 Collinge, W.H. \& Harty, C.F. (2014). Stakeholder interpretations of design: semiotic insights 484 into the briefing process. Construction Management \& Economics, 32(7-8), 760-772.

485 Cranwell, R.M. \& Hunter, R.L. (1997). Architectural design for reliability. Paper presented 486 at the Conference on Architectural Surety: Assuring the Performance of Buildings and 487 Infrastructures, Security Systems and Technology Center, Albuquerque, New Mexico, USA. 488 May 14-15, pp.121-124.

489 Dainty, A., Moore, D. \& Murray, M. (2006). Communication in construction: Theory and 490 Practice. Oxon: Taylor and Francis.

491 Davies, S.C. (2013). Annual report of the Chief Medical Officer. Volume Two, 2011:

492 Infections and the rise of antimicrobial resistance.

493 https://www.wp.dh.gov.uk/publications/files/2013/03/CMO-Annual-Report-Volume-2$494 \quad$ 20111.pdf

495 Department of Health. (2013). Health Building Note 00-09: Infection control in the built 496 environment. London: HMSO. 
497 Emmitt, S. \& Gorse, C. (2007). Communication in construction teams, Oxon: Taylor and 498 Francis.

499 Gluch, P. \& Raisanen, C. (2009). Interactional perspective on environmental communication 500 in construction projects. Building Research \& Information, 37(2), 164-175.

501 Green, S. D. (1996). A metaphorical analysis of client organizations and the briefing process. 502 Construction Management and Economics, 14(2), 155-164.

503 Hamilton, D. Kirk. (2013). Design and infection: a call for greater progress through research. 504 Health Environments Research and Design Journal: Special Issue, 7(1), 140-142.

505 Kamara, J. M., Anumba, C.J. \& Evbuomwan, N.F.O. (2000). Establishing and processing 506 client requirements - a key aspect of concurrent engineering in construction. Engineering, 507 Construction \& Architectural Management, 7(1), 15-28.

508 Kao, C. \& Green, S.D. (2002). The briefing process: a knowledge management perspective. 509 Paper presented at the Chartered Institute Of Building Value Through Design Conference 510 Rotterdam (eds: Gray, C. and Prins, M.), 81-92.

511 Kazmierczak, E.T. (2003). Design as meaning making: from making things to the design of 512 thinking. Design Issues, 19(2), 45-59.

513 Markus, T.A. \& Cameron, D. (2002). The words between the spaces: buildings and language. 514 London: Routledge.

515 Medway, P. (1996). Writing, speaking, drawing: the distribution of meaning in architects` 516 communication. In Sharples, M. \& ven der Geest, T. (Eds.), The New Writing Environment: 517 Writers at work in a world of technology. London: Springer Verlag.

518 NHS Estates (2002). Infection control in the built environment, London, HMSO. 
519 Stockley, J. M., Constantine, C.E. \& Orr, K.E. (2006). Building new hospitals: a UK

520 infection control perspective. Journal of Hospital Infection, 62, 285-299.

521

522

523

524

525

526

527

Refurbishment/Disposal

528

529

530

Figure 1: Different phases of construction project lifecycle (adapted from Cranwell and Hunter, 1997)

531 


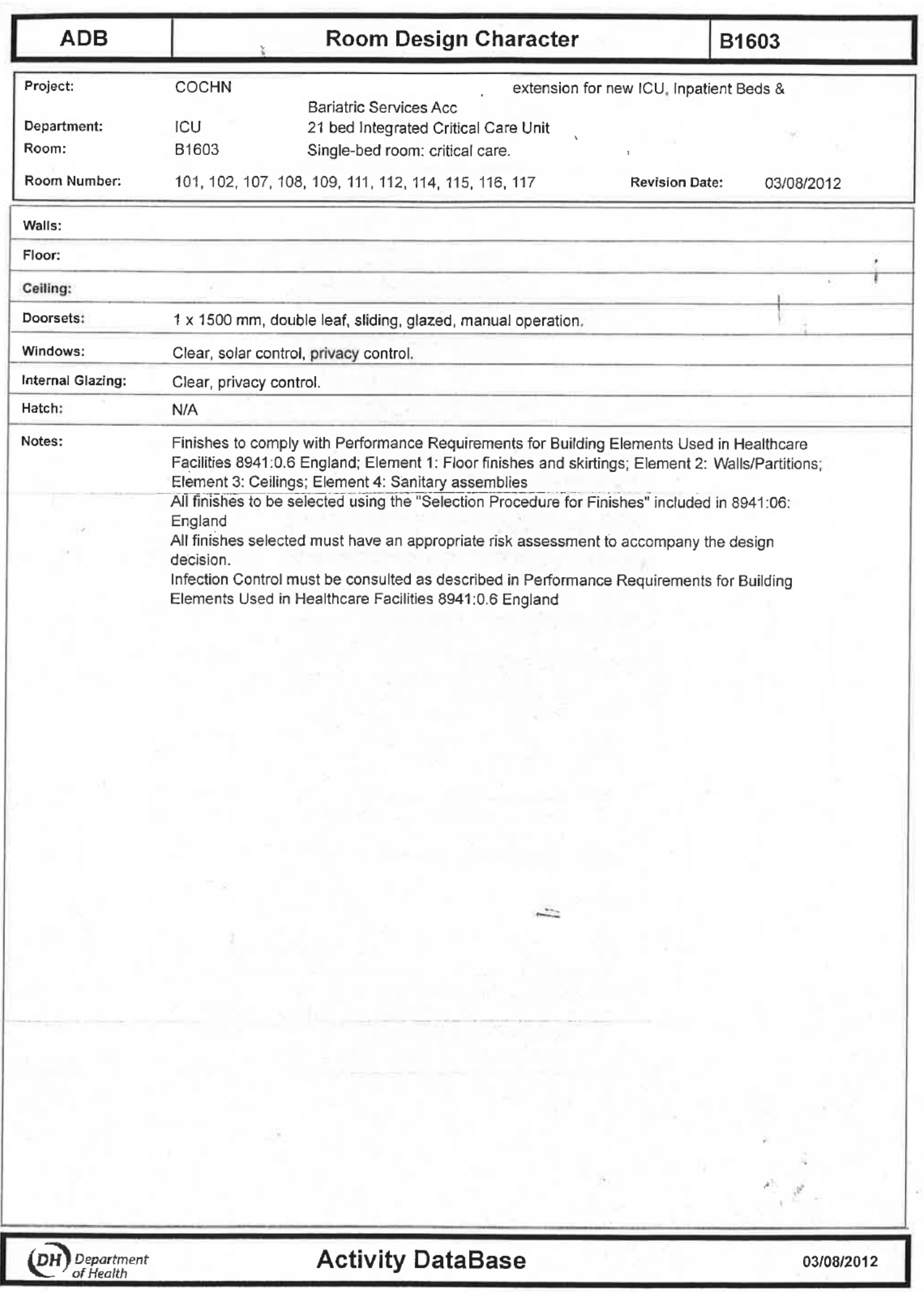

